\title{
A Theoretical Analysis of Sea-Ice Strength
}

\author{
Don L. Anderson and Wilford F. Weeks
}

\begin{abstract}
For the first time an attempt is made to derive a theoretical relationship between sea-ice strength and the controlling factors of salinity, temperature, and density. A geometric model of the ice-brine relationship is constructed from photographs and used to calculate tensile strength of warm (above $-20^{\circ} \mathrm{C}$ ) sea ice. The theoretical results compare well with experimental data. The model developed can be extended to colder temperatures by considering the effect of solid salts.
\end{abstract}

Background-When sea water freezes, small flat plates of pure ice form, leaving behind a concentrated brine which tends to drain out of the ice. However, a certain amount of the brine is retained between the ice plates in layers or pockets, causing the sea ice as a whole to be salty. In general, the faster the ice grows, the more brine is trapped. When the ice first forms, the flat ice plates float on the surface of the water with their c axes vertical, forming a very weak, highly saline mush of overlapping plates. As the ice thickens the plates grow at an angle to the surface, and, at about $1.5 \mathrm{~cm}$ from the top, depending on the freezing conditions, vertical plates, with the $\mathrm{c}$ axes horizontal, predominate. In lake ice, on the other hand, the $c$ axis often remains vertical throughout the thickness of the ice, and long, candle-shaped crystals are formed. The small plates alternating with layers of brine occur in bundles which appear as single crystals under crossed polaroids.

The temperature and salinity of the ice determine the amount of brine and hence the thickness of the brine layers. The salinity of the brine is much greater than that of the original sea water and depends on the temperature of the surrounding ice with which it is in thermal equilibrium. As the sea ice becomes colder, more ice freezes out of the brine, which becomes more concentrated. With a temperature rise, ice melts and the brine becomes diluted. These brine layers shrink as the temperature decreases and finally 'neck' and separate into vertical cylinders which often extend entirely through the ice sheet. These brine cylinders are separated by ice 'bridges' which connect the original plates. The separation of the layer is controlled predominantly by surface tension. The cylinders are therefore circular or elliptical in horizontal section. The process of the brine-layer separation into cylinders is shown diagrammatically in Figure 1. The hatched area is brine.

Figure 1a is a horizontal section (plan view) showing ice plates separated by brine layers. In
Figure $1 \mathrm{~b}$ the brine layers have begun to 'neck,' and in 1c the brine layer has separated into cylinders. Figure 1d shows the orientation of elliptical cylinders-the short axis of the ellipse is always perpendicular to the ice plates. With a further temperature drop the radii of the cylinders decrease. In the case of elliptical cylinders the long axis shrinks faster than the short, and the cross section approaches a circle. Figure $2 \mathrm{a}$ is a photograph of a horizontal section of sea ice in which the layers have begun to 'neck.' In Figure 1c and $2 \mathrm{~b}$ the layers have split into rows of cylinders. Figure $2 \mathrm{~d}$ is a vertical section of the same ice. Note the length of the brine pockets. Figure if is a three-dimensional schematic sketch of the icebrine relationship. Fig. 2c shows badly deteriorated ice.

Ideally, a row of equally spaced, equal-diameter, circular cylinders will be formed. Actually, ellipses are more common, and spacing and dimensions vary widely. Often the brine layer splits into two or more parallel rows of cylinders. The possible complexity of the broken brine layer is evident in the photographs.

These cylinders stay long in relation to their diameter because of gravity and the thermal gradient across the ice. They are unstable and migrate to the warmer temperature, which in winter is the lower surface of the ice [see Veinberg, 1940]. This causes brine to drain out of the ice even under very cold conditions. The salinity of the ice therefore decreases from its initial value of 15 to $20 \%$ to about $5 \%$ late in the first season. The various constituents of the brine crystallize out as their eutectic point is exceeded. Sea ice probably never becomes completely solid under natural conditions. The presence and geometry of these brine pockets are the controlling factors in the strength of the sea ice. The present analysis is limited to warm ice. No attempt is made to determine the quantitative effect of solid salts.

When sea ice breaks in tension or flexure, it 


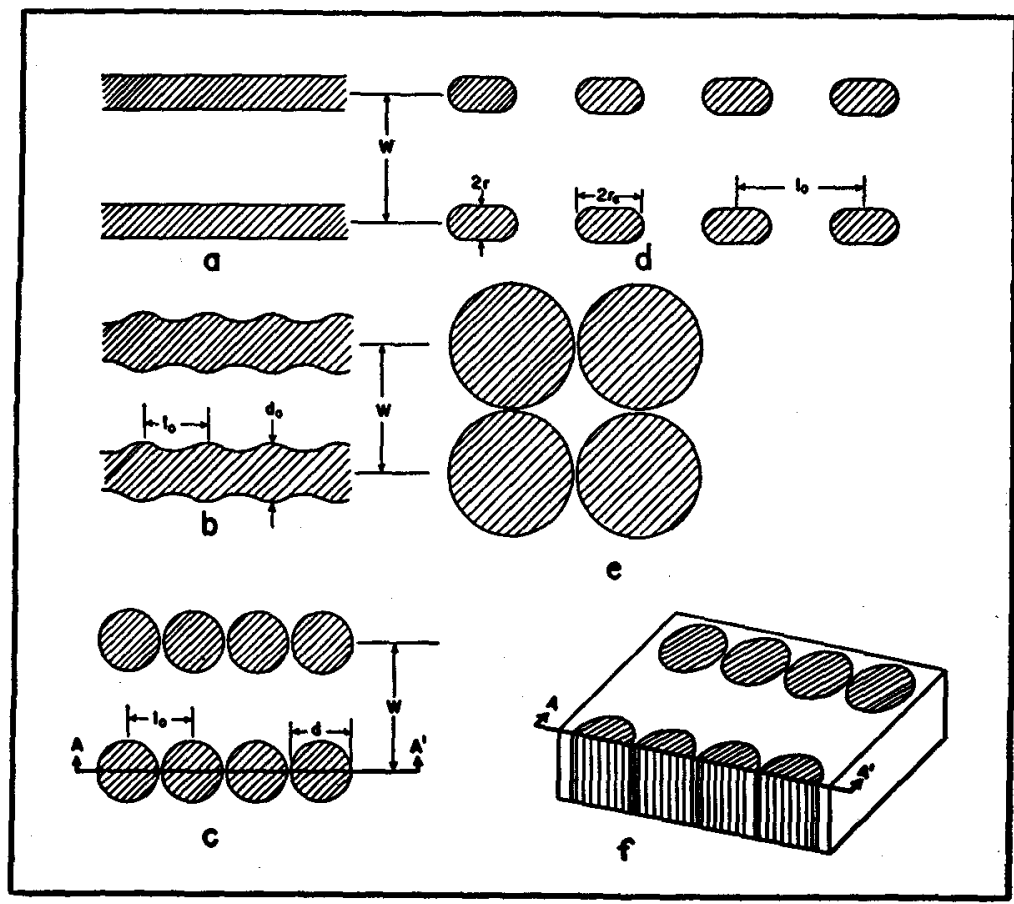

FIG. 1 - Schematic diagrams showing how a brine layer splits into cylinders; see text for details

breaks primarily along these brine cells, parallel to the small plates. Figure 3 is a rubbing of a horizontal section of an ice beam that has been broken. The parallel lines are the edges of single plates. Each group of parallel lines is a crystal. Sea-ice failure surfaces are usually irregular because of this tendency to break along the plate boundaries.

Sea-ice model-To derive a theoretical relationship between strength and the controlling factors of salinity and temperature, we shall use the above information to construct a simplified model. We will consider the strength in tension since a loaded ice sheet usually fails in tension.

Consider a small, thin slab of sea ice in which the brine cylinders go all the way through. In Figure 1c let $A-A^{\prime}$ be the line of break. The direction of tension was at right angles to this line. The strength of the ice depends on the area of the cross section normal to the tension. Because of the presence of the brine the effective cross-sectional area is reduced.

Let $\beta_{\varepsilon}=d / l_{o}$ where $\beta_{e}$ is the amount of brine in a unit area of the failure plane, $d$ is the diameter of the cylinders, and $l_{o}$ is the cylinder separation in the failure plane (Fig. 1). The effective width of the area is then $\left(1-\beta_{e}\right)$, considering unit thickness. In the case of ellipses, $\beta_{e} \cong 2 r_{e} / l_{o}$.
The strength of the sea ice $\sigma$ then will be a function of the form

$$
\sigma \sim \sigma_{p}\left(1-\beta_{e}\right)
$$

where $\sigma_{p}$ is the strength of the ice with no brine cells, that is, pure ice.

The brine cells also act as stress concentrators. The highest stress will be on the edge of the cylinder normal to the direction of tension, and this will be the point of initial failure. A single, round, cylindrical hole in an infinite plate will have a tangential stress on its boundary equal to three times the applied stress. An elliptical hole with its long axis normal to the tension will have an even larger stress concentration [see, for instance, Timoshenko, 1934]. The failure surface will spread perpendicular to the direction of tension-in this case, along the row of holes. The apparent strength of a slab in the vicinity of a hole is one third of the strength with no hole. Actually, with only a few holes the strength may not be reduced to this extent except under repeated loadings. The crack will spread slightly with each loading, and finally the slab will fail by fatigue. With the numerous 'flaws' in sea ice, however, the cracks intersect, and we may consider that the strength under single loading is immediately reduced.

The stress-concentration factor $k$ is defined as 


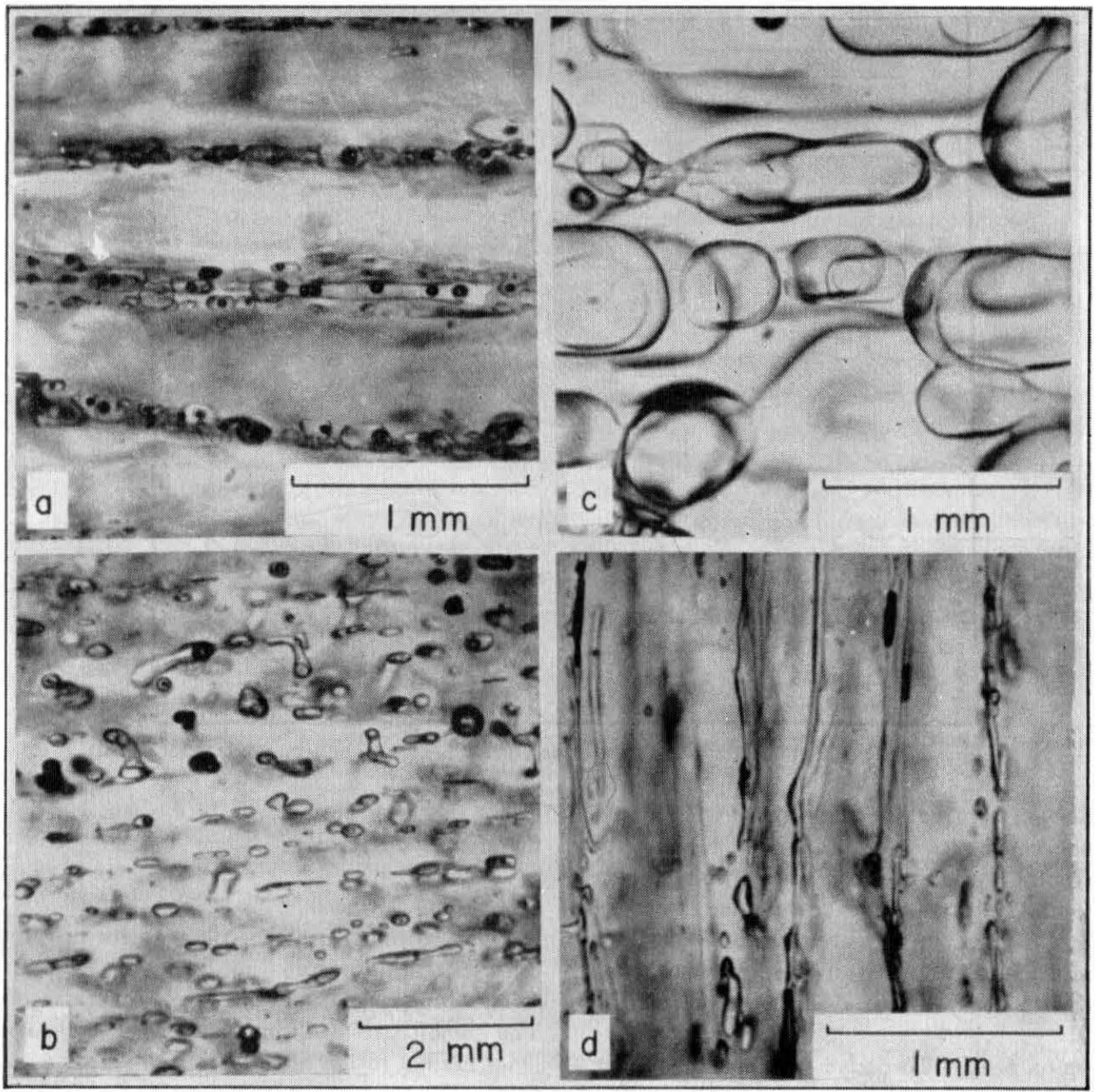

FIG. 2 - Photomicrographs of sea ice, showing brine-ice relationship

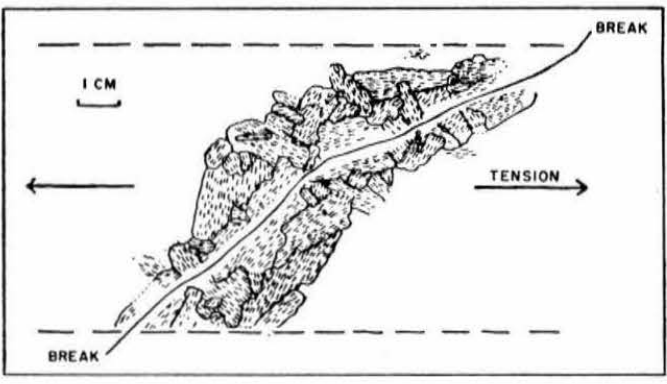

FIG. 3 - Rubbing of a broken segment of sea ice

the ratio of the maximum stress to the average stress in the minimum section. The stress in the minimum section is the force on the end of the slab divided by the effective cross-section area.

Thus, considering the ice at its breaking point

$$
k=\sigma_{p}\left(1-\beta_{\epsilon}\right) / \sigma
$$

This puts the strength equation in the form

$$
\sigma=\sigma_{p}\left(1-\beta_{e}\right) / k
$$

When the ice is very cold and the brine pockets are small and far apart, we have essentially isolated holes in an infinite plate. As the ice warms and the brine pockets become larger and their edges closer together, the stress concentration factor decreases rapidly. There are, however, usually many small brine pockets scattered between the large ones; these are remnants of the brine that went to form the large cylinders. These small cylinders are effective stress concentrators and will always have a stress concentration at their boundary of approximately three. The relation between strength and $\beta_{e}$ is shown in Figure 4 for a row of equally 


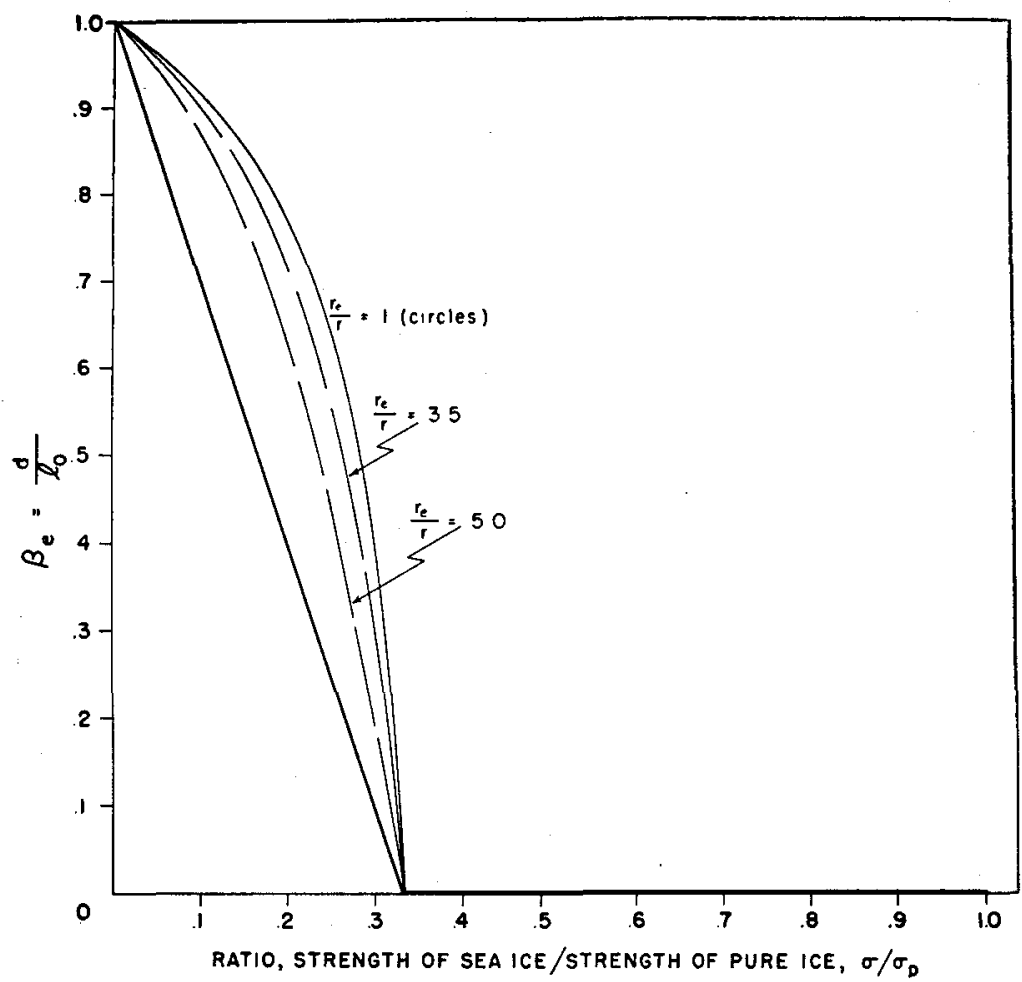

FIG. 4 - The effect on the strength of the amount of brine $\left(\beta_{\epsilon}\right)$ and brine orientation along the failure plane

spaced circles and also for a row of ellipses with different axis ratios. The curves, for the most part, are sketched from experimental data of Frocht [1935] and Capper [Howland, 1935] and a theoretical solution by Howland [1935].

As the long axis of the ellipse increases, the curves approach the straight line which represents a constant stress concentration of three, the case where there are always small 'remnant' cylinders. This straight line gives the minimum strength at all times; the curve representing the row of circles gives the maximum. Since the ice will break where the strength is minimum, we shall use the straight line which represents a constant stress concentration of three. The curves all approach 0.33 on the abscissa because with a small brine content the brine pockets are mostly circular.

The slopes of the curves are discontinuous at $\beta_{e}=0$ and jump to the strength of pure ice. As $\beta_{e}$ approaches unity, the strength goes to zero. When $\beta_{e}$ is small but the ice is still warmer than approximately $-20^{\circ} \mathrm{C}$, the strength is one-third that of pure ice. In very cold ice this strength reduction appears only upon repeated loading, as mentioned above. Note that lake ice is not necessarily 'pure' ice because of the presence of minute flaws.
Other factors tend to depress the strength value from the ideal row of circular holes. Unequal spacing, varying diameters, and irregular shapes will all increase the stress concentration and decrease the effective cross-sectional area.

Measurements from photographs-If $l_{o}$, the brine pocket separation, has a relation to $W$, the plate width, or if $W$ is constant, then $\beta_{e}$ can be related to $\beta$, the brine content by volume, of the ice. From about 50 measurements on photographs of sea ice under many conditions from a variety of locations, $W$ was determined to be $0.46 \mathrm{~mm}$ with a small deviation from this value. Several measurements by Fukutomi and others [1952] show an average value of $0.39 \mathrm{~mm}$. Nakaya [1956] describes a layer structure in pure ice crystals revealed by Tyndall figures. He determines the mean width of these plates to be $0.5 \mathrm{~mm}$. Apparently the plates forming sea-ice crystals are equivalent to the plates in pure ice, but because of the brine layers the plate structure in sea ice is much more evident. This also suggests that impurities cause the plate structure in 'pure' ice.

A similar number of measurements from photographs of brine layers which have broken into round cylinders show the average distance between 
cylinders, $l_{o}$, to be $0.23 \mathrm{~mm}$, just half the plate width, but with a large range of variation. If the separation of the brine layer into cylinders is governed by surface tension, the distance between the cylinders will be related to the width, $d_{o}$, of the brine layer just before separation and the diameter $d$ of the cylinder just after separation.

From Nakaya [1956]

$$
\begin{aligned}
d / d_{o} & =2(1+\epsilon) \cong 2 \\
l_{o} / d & =(\pi / 2)(1+\epsilon) \cong \pi / 2=1.57 \\
\therefore d_{o} / l_{o} & \cong 0.32
\end{aligned}
$$

where $\epsilon$ is a very small value, not determined. From photographs of layers just before and after splitting, an average of many values shows $d_{o}=$ $0.07 \mathrm{~mm}, l_{o}=0.23 \mathrm{~mm}, d=0.136 \mathrm{~mm}$, giving $d_{o} / l_{o}=0.30$, and $d / d_{o}=1.94$.

The agreement of these ratios seems to indicate that surface tension is the controlling factor. This agreement is remarkably good, considering that measurements could not be made immediately before or after the breaking of the layer in cylinders. When the brine layer splits into elliptical cylinders, the spacing of the centers is about the same as the plate width, indicating that an ellipse is simply two joined circles. As the ellipses shrink, they may break again. When a brine layer splits into ellipses, the short dimension $2 r$ stays about $0.07 \mathrm{~mm}$.

Converting to brine content-The brine content $\beta$ of the ice is the ratio of the volume of the brine to the total volume. In the case of round cylinders

$$
\beta=\frac{1}{4} \pi d^{2} / l_{o} W=\pi d^{2} / 4 a l_{o}^{2}=\pi \beta_{e}^{2} / 4 a
$$

where $a=W / l_{o}$.

For 'elliptical' cylinders [not true ellipses]

$$
\begin{aligned}
\beta & =\left\{\frac{1}{4} \pi(2 r)^{2}+\left(2 r_{e}-2 r\right)(2 r)\right\} / l_{0} W \\
& =\frac{\pi r^{2}+\left(\beta_{e} l_{0}-2 r\right)(2 r)}{a l_{0}^{2}}
\end{aligned}
$$

Just before the layer breaks into cylinders $\beta=$ $d_{o} / W \cong 0.07 / 0.46 \cong 15.2$ pct by volume.

This indicates that ice with more than about 15.2 pct by volume of brine has no strength. This no-strength condition is the skeleton layer phenomenon mentioned by Weeks and Anderson [1958]. The skeleton layer, then, has a brine content of at least 15.2 pct by volume. This high brine content on the bottom of the sheet is due to high salinity caused by brine drainage and the high temperature of the underlying water.

When very cold ice is warmed, the brine cyl- inders expand until they reach a diameter of about $0.07 \mathrm{~mm}$ and then spread out along the plates until they touch and coalesce. The layers then increase in width until the ice is entirely melted. Less commonly, the cylinders stay circular and increase in diameter until they touch and coalesce (Fig. 1e and 2c).

To relate $\sigma$ to $\beta$, we use (4) or (5), depending on the shape of the brine pockets. For circular pockets, (3) and (4) give

$$
\sigma=\frac{\sigma_{p}}{k}\left[1-\left(\frac{4 a \beta}{\pi}\right)^{\frac{1}{2}}\right]
$$

where $a$ depends on the brine-pocket separation.

For 'elliptical' pockets, (3) and (5) give

$$
\sigma=\frac{\sigma_{p}}{k}\left[1-\frac{a l_{0}^{2} \beta-\pi r^{2}+4 r^{2}}{2 r l_{0}}\right]
$$

Since $l_{o}, r$, and $a$ are all measured, this reduces to

$$
\sigma=\frac{\sigma_{p}}{k}\left[1-\frac{0.2116 \beta+0.0011}{0.0322}\right]
$$

where $a=1$.

Introducing temperature and salinity-Brine content $\beta$ is a function of both temperature and salinity. In $m$ grams of sea ice of salinity $S_{i} \%$, there are $n$ grams of brine of salinity $S_{b} \%$ [Malmgren, 1927].

$$
n / m=S_{i} / S_{b}
$$

where $n / m=\beta_{w}$ (pct brine content by weight). This formula holds until solid salts begin to pre-

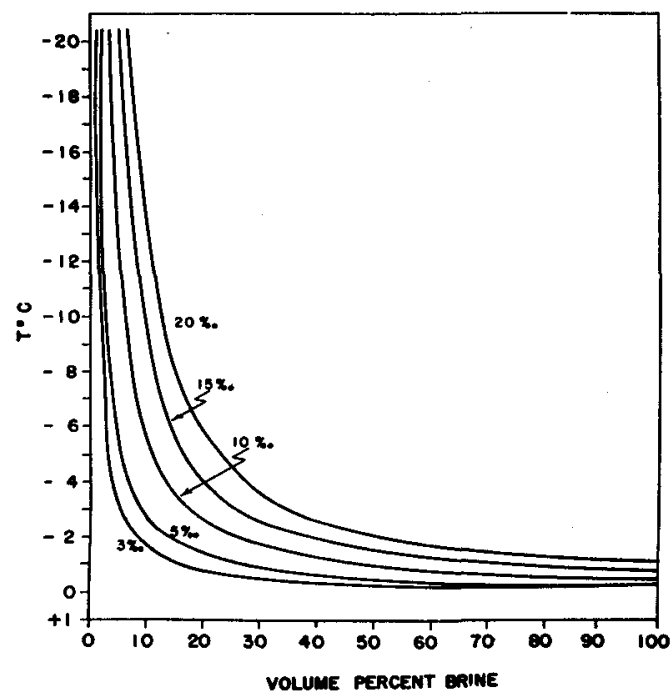

FIG. 5 - The amount of brine, by volume, in sea ice in relation to temperature at various values of ice salinity 
cipitate. It is fairly accurate to $-22.9^{\circ} \mathrm{C}$ when the sodium chloride starts to crystallize. At this point approximately 3.2 grams of $\mathrm{Na}_{2} \mathrm{SO}_{4} \cdot 10 \mathrm{H}_{2} \mathrm{O}$ have already precipitated in 1000 grams of sea ice.

With every $S_{b}$ there is associated a temperature, because of previously noted equilibrium considerations; and with every temperature there is associated a density of pure ice, a density of brine, and, combining the two, a density of sea ice.

The relation between $\beta$ and $\beta_{w}$ is [Veinberg, 1940]

$$
\beta=d_{i} \beta_{w o} / d_{b}
$$

where $d_{i}=$ density of sea ice, and $d_{b}=$ density of brine.

Therefore, knowing the temperature and salinity of the ice we can determine the brine content by volume, which we have already related to strength. Brine content by volume is plotted against temperature for various salinities in Figure 5. A more accurate curve, taking into account solid salts, has recently been developed by one of the authors (unpublished manuscript by DLA, Some Properties of Sea Ice).

The only quantity now lacking in (7) and (8) is the strength of pure ice. The best experimental values for the tensile strength of pure ice were obtained by Butkovich [1954]. His values for the relation of tensile strength of pure ice to temperature are essentially the same as those of Wilson and Horeth [1948] in flexure. Butkovich's values are used as the starting points in our curves, although they must be considered as only a first approxima-

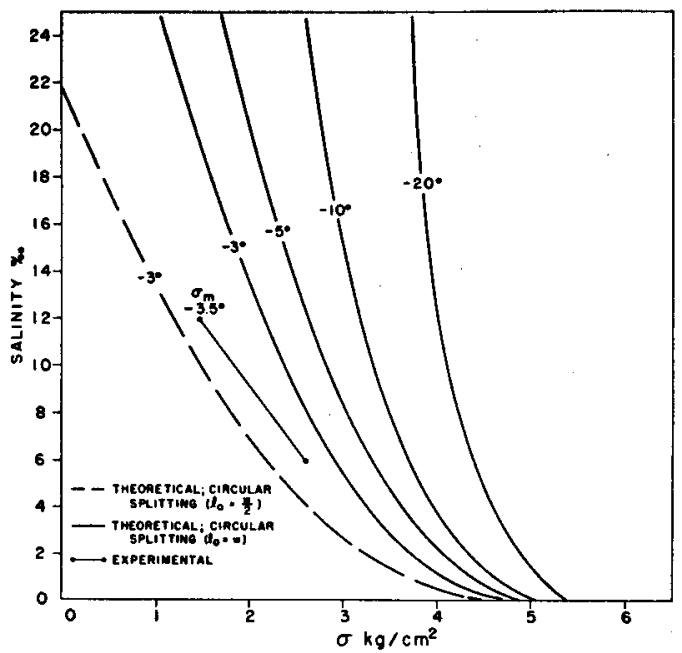

Fig. 6-The relation between tensile strength and salinity at various temperatures for circular splitting of the two different cylinder spacings

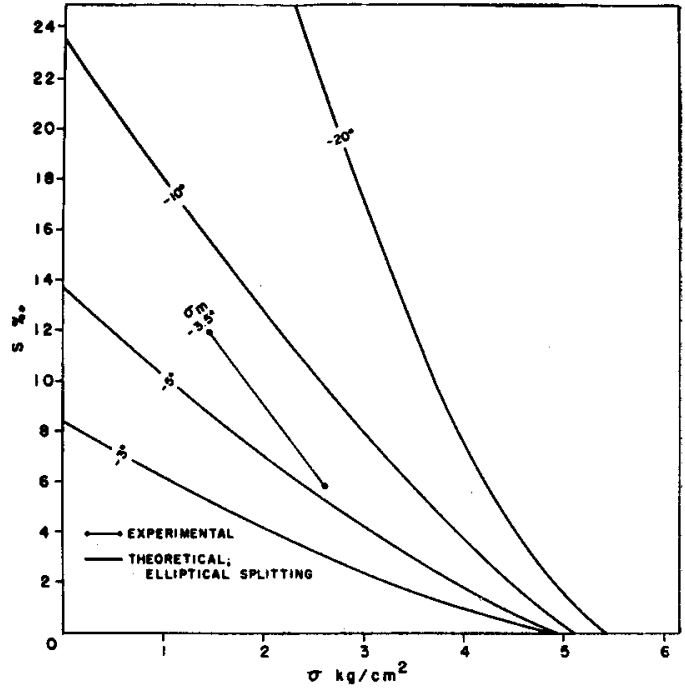

FIG. 7 - The relation between tensile strength and salinity at various temperatures for elliptical splitting

tion to the actual strength of the small ice bridges. Butkovich's values are not obtained from perfectly pure ice and we also know that very small volumes give a higher strength than larger volumes. We can, however, obtain relative strengths by using these values. Pure ice may be up to three times as strong as reported by Butkovich.

Values for strength versus temperature and salinity are plotted in Figures 6 and 7. Figure 6 assumes that the brine pockets enlarge as circular cylinders until they coalesce. Two different cylinder spacings are plotted for $t=-3^{\circ} \mathrm{C}$. The lower dashed curve is for $a=2$; the solid curves for $a=$ 1. The short curve shows experimental data [Weeks and Anderson, 1958]. Figure 7 assumes that the cylinders remain circular until $d=0.07 \mathrm{~mm}$ and then expand as ellipses. This happens when $\beta$ is 3.6 pct. Spacing does not appreciably change the curves in this latter figure. As stated before, the ellipses are more common, and, since they cause lower strength, they would be expected to be especially common along the line of break. The value of $k$ is assumed to be a constant three in the two preceding curves. The short curve is from the experimental data. In the experimental analysis the average temperature of the entire ice sheet was used. The beam tests are not directly comparable with theoretical results in tension. The result of stress concentration at the end of the cantilever has been ignored, and a constant cross section has been assumed in the experimental work.

Other investigators-Butkovich [1956] reports val- 
ues for in-place beam tests on sea ice between 2.21 and $3.98 \mathrm{~kg} / \mathrm{cm}^{2}$ for ice temperatures from -5 to $-8^{\circ} \mathrm{C}$ and salinities of approximately 5 to $8 \%$. Assur [Butkovich, 1956] reports values of 1.1 to $4.9 \mathrm{~kg} / \mathrm{cm}^{2}$, with no temperatures or salinities given. All of these values are within the areas of the curves. Many values in the literature are lacking temperature and salinity control, without which they have little meaning. Most of these tests were made on very small beams which were removed from the water. With very cold air temperatures and low salinities these samples can give results approaching and even exceeding the strength of fresh ice. Petrov [1955] and Assur (personal communication, 1956) report that very cold sea ice can have higher strength than lake ice. In these cases the ice has been exposed to a very cold air temperature, and the solid salts act as binders rather than stress concentrators. The warm underside of the ice is the point of initial failure under most conditions in situ. In the ice sheet the majority of the ice never experiences extreme cold because of the presence of the warm water. Also the different orientation of the crystals in sea ice would affect the strength.

Butkovich [1956] also reports results of small-ring tensile tests on sea ice. These values show a greater strength than the in-place tests reported by him and are also higher than the present writers' values. The small-ring tensile tests cause a break parallel to the applied force and extending between the points of application of the force. The break, then, is forced to cross crystal and plate boundaries, causing a much higher apparent strength. A statistical study of the plate size and orientation would permit a maximum, minimum, and average strength to be calculated, using the theory developed in this paper. Also, other type strength tests may be approached similarly.

Small beam tests seem to give values approximately 2.6 times greater than in-place cantilevers. Ring tests give results up to four times higher.

Even if the results of the two methods of testing are not at present directly comparable, they should give a similar strength, temperature, and salinity relationship. Butkovich performed 137 ring tests under a variety of temperatures and a small range of salinities, making them very valuable for giving the temperature dependency of the strength of sea ice. Plotting temperature versus strength for his ring tests for a constant salinity of $5 \%$ gives us the curve to the right in Figure 8. Each point is an average of about ten values. The curve indicates that, for a decreasing

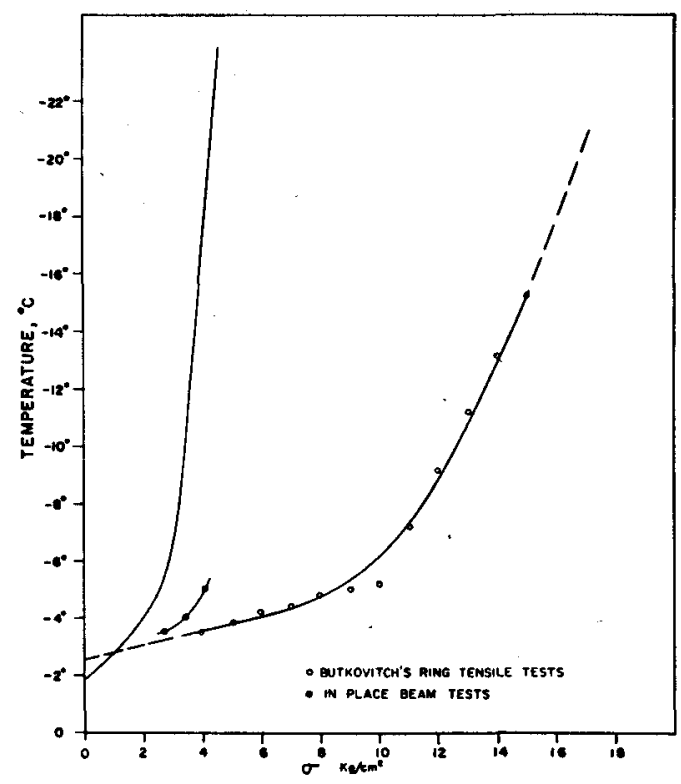

FiG. 8-Relation between temperature and strength for sea ice of a salinity of $5 \%$; the solid curve is theoretical, elliptical splitting

temperature, strength increases rapidly at first and then more slowly. The theoretical results (curve at left) show a similar tendency and compare reasonably well, remembering that we are not comparing values of strength but changes in strength with temperature. The inflection point for both curves is about $-5^{\circ} \mathrm{C}$. Extrapolating the experimental curve to no strength gives us, very roughly, $11 \mathrm{pct}$ brine by volume (Fig. 5).

By converting the brine contents at a salinity of $5 \%$ and the various temperatures, as given in the curve, to the same brine content at different temperatures and salinities, and allowing for the difference in strength of the pure ice 'bridges,' a family of curves giving strength versus salinity and temperature for the small-ring tests can be constructed.

The short curve gives the results of Weeks and Anderson [1958]. Because of the limited temperature range available in thin, in-place beams, this curve is very rough, but it extrapolates to about the same brine content at no strength as predicted in the theory.

Effect of enclosed air-The air content of sea ice can be very considerable. The air bubbles tend to concentrate in the brine pockets, and they have approximately the same effect on strength as adding a similar amount, by volume, of brine. Ice that has formed very rapidly under very cold conditions, or ice that has formed under turbulent 
conditions, is especially able to trap a large amount of air. Therefore, most of the air in young ice is near the top. As ice ages, the brine drains out and is largely replaced by air, giving old ice a considerable air content throughout its thickness.

The air content is reflected in the density. As stated before, the temperature and salinity completely define the density of air-free ice. The difference between measured and computed density is due to air. The air content can simply be added to the brine content when roughly calculating the strength of sea ice.

The density of warm sea ice can be obtained from (9) and (10).

$$
d_{i}=\beta d_{b} S_{b} / S_{i}
$$

Values of sea-ice density are published in Malmgren [1927], Sverdrup and others [1942], Zubov [1945], Veinberg [1940], and Dorsey [1940], as well as in some standard engineering and oceanographic tables.

In a sample computation for ice of $5 \%$ salinity and temperature of $-7^{\circ} \mathrm{C}$, the density is determined to be 0.925 . If the measured density is, for instance, 0.920 , then 0.005 grams of brine per cubic centimeter of ice have been replaced by air and we must add $\left(0.005 / d_{b} \times 100\right)$ pct to the brine content obtained from the measured salinity and temperature. This calculation will also take into account original air. Because of the inherent inaccuracies of measuring density, temperature, and salinity, we can assume $d_{b}$ to be one gram per cubic centimeter and thus convert the difference in density immediately to extra brine content because of air. Thus, from Figure 5 a temperature of $-7^{\circ} \mathrm{C}$ and salinity of $5 \%$ gives a brine content by volume of 4 pct. Adding to this 0.5 pct for the air gives us a $\beta$ for computation purposes of 4.5 pct by volume.

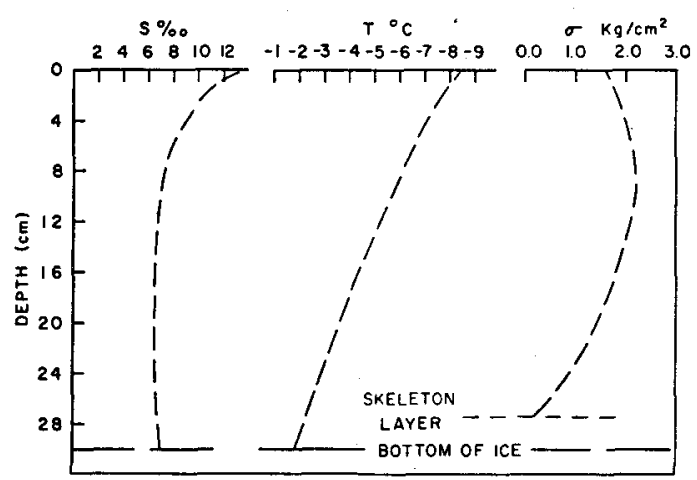

FIg. 9 - Typical salinity, temperature, and strength profiles through a sea-ice sheet
Conclusions-Because of the complexity of sea ice the derived formulas and curves are necessarily very general, but they give a first and, we believe, an accurate picture of the relation between strength and the major controlling factors.

The following considerations enter into a more detailed analysis of sea-ice strength:

(1) Surface tension probably has an appreciable effect on the cohesion of the ice plates.

(2) Sometimes the brine pockets do not entirely pierce the section under consideration vertically. This will not materially change the argument for tension, since for a given $\beta_{e}$ the effective crosssectional area will be the same, regardless of distribution of the brine. However, as can be seen from the flexural strength formula, the distribution of the brine materially affects the results of flexural calculations. If the brine pockets do not entirely pierce the section, then the effective thickness, as well as the effective width, will be changed.

(3) The argument is developed for thin sheets in which the temperature and salinity are constant throughout. A thicker sheet is made up of many layers, each with its own temperature, salinity, and strength. A complete analysis of the strength of thick ice must include a variation of the constants throughout the section. A variable cross section should be used in calculation. Figure 9 gives a typical temperature and salinity profile through the sheet, and a strength profile using results from Figure 7 .

(4) The geometry of the brine pockets, especially along breaks, must be studied further. The constants $a, 2 r$, and $k$ can be changed, if necessary, as a result of further measurement, and perhaps the factors controlling the magnitude of these constants can be determined.

(5) The assumption of a constant $k$ may fall down at high brine content when all the brine pockets are large, and at very low brine content. The theoretical strength at high temperature and salinity may be too low. The theory is general enough to include changes in stress concentration.

(6) The effects of plasticity and recrystallization have not been considered.

(7) Only breaks parallel to the small plates have been considered. Certain small-scale strength tests cause the ice to artificially break across the plates. Other tests load the ice parallel to the optic axis or to other directions which do not occur in an inplace ice sheet. Also, shear, torsion, impact, and compression tests are commonly performed. These tests can also be considered theoretically. Tensile, 
or flexural, strength is usually the only strength property that is important in calculating the bearing strength of an ice sheet. The tensile strength of the warm underside of the ice is the most important single quantity.

(8) Inter-plate slippage may prove to be an important factor, especially in slowly applied loads.

(9) The quantitative effect of solid salts on very cold ice has not been considered in the present analysis. Work is continuing on this problem.

(10) 'Pure' lake ice itself has many stress concentrators, mostly minute air bubbles. If it is determined that these stress concentrations actually affect the strength by a factor of three, the numerical results reported in this paper are low. The formulas developed are still valid until solid salts precipitate in quantity but a higher value of $\sigma_{\mathrm{p}}$ must be used in numerical computations. $\sigma_{\mathrm{p}}$ refers to absolutely pure ice and has probably never been measured except possibly on very small samples. The ability of warm ice and ice next to the liquid phase to maintain a stress concentration must be studied. If the ice is not perfectly elastic, we would expect the stress concentration to be low in warm ice and to approach three in colder ice.

Acknozvledgmenis-Field observations used in this study were made as part of the Sea Ice Bearing Strength Project, a joint effort of the Air Force Cambridge Research Center, the Snow, Ice, and Permafrost Research Establishment (SIPRE), and the Navy Hydrographic Office. We wish to thank A. Assur and T. R. Butkovich for their advice on many of the problems associated with this study. A. Assur and E. Little kindly read the manuscript and offered many helpful suggestions. L. Hansen of SIPRE allowed the authors to use the unpublished results of his in-place cantilever beam tests. John Grady and Eugene Whitney provided invaluable assistance during the period of testing at Thule, Greenland. Photographs are by W. F. Weeks.

\section{REFERENCES}

ButKovich, T. R., Ultimate strength of ice, SIPRE Research Paper 11, 12 pp., 1954.
BUTKovich, T. R., Strength studies of sea ice, SIPRE Research Paper 20, 15 pp., 1956.

DoRsey, N. E., Properties of ordinary water-substance, A.C.S. Monograph Series 81, Reinhold, New York, 656 pp., 1940.

FrOCHT, M. M., Factors of stress concentration photoelastically determined, J. Appl. Mech., 2, A67-68, 1935.

FuKUTom, T., M. SAITo, ANd Y. Kudo, 16 th report on a study of sea ice, Low Temperature Institute, Hokkaido Univ., 12 pp., 1952.

HowLAND, R. C. J., Stresses in a perforated plate, Proc. R. Soc., London, A, 148, 471-491, 1935.

Malmgren, F., On the properties of sea ice, Sci. Res., Norwegian North Pole Exped. with the Maud, 19181925, 1(5), 67 pp., 1927.

Nakaya, U., Properties of single crystals of ice, revealed by internal melting, SIPRE Research Paper 13,80 pp., 1956.

Petrov, I. G., Physical-mechanical properties and thickness of the ice cover, Observational data of the Scientific-Research Drifting Station of 1950-1951, ed. by M. M. Somov, Leningrad, Izd. 'Morskoi Transport,' pp. 1-42, 1955. (Trans. by Amer. Met. Soc, 2(6), 60 pp. +42 tables, 1957).

SVERdRUP, H. U., M. W. Johnson, AND R. H. Fleming, The Oceans, Prentice-Hall, New York, 656 pp., 1942.

Timoshenko, S., Strength of materials, pt 2, Advanced theory and problems, Van Nostrand, New York, 498 pp., 1934.

VEINBERG, B. P., Led: svoistva, vozniknovenie $i$ ischesznovenie l'da (Ice, its properties, origin and disappearance), Gosizdat, Tekhniko-teoreticheskoi Literatury, Moscow, 1940.

Weers, W. F., AND D. L. Anderson, An experimental study of strength of young sea ice, Trans. Amer. Geophys. Union, 39, 641-647, 1958.

WILSON, J. T., AND J. M. HORETH, Bending and shear tests on lake ice, Trans. Amer. Geophys. Union, 29, 909-912, 1948.

Zubov, N. N., L'di Arktiki (Arclic ice), Izdatel'stvo Glavsevmorputi, Moscow, 1945.

Geophysics Research Directorate, Air Force Cambridge Research Center, Bedford, Massachusetts (D. L. A.) and Washington University, St. Louis 5, Missouri (W. F. W.).

Manuscript received September 5, 1957; presented at the Thirty-Ninth Annual Meeting, Washington, D. C., May 6, 1958; open for formal discussion until January 1, 1959.) 